\title{
Tutoring Junior Students by Senior Students in Engineering Courses
}

\author{
Uma Boregowda $^{1}$, Sunitha ${ }^{2}$ P, Geetha Kiran ${ }^{3}$ A., Chandrashekar ${ }^{4}$ H. S. \\ umaboregowda@gmail.com \\ 22suniachar@gmail.com \\ 3geethamk@gmail.com \\ ‘hsc@mcehassan.ac.in
}

\begin{abstract}
In an attempt to improve student learning in terms of acquired knowledge and its applicability, the idea of using senior undergraduate students to tutor junior undergraduate students is attempted. The goal of the tutoring program is to provide an interactive atmosphere that will help junior computer science students to better understand the fundamental and advanced concepts, and also to provide an opportunity for senior students to develop teaching, organizational and leadership skills. This paper illustrates the approach experimented at our department for the course on microprocessor. The approach is based on the use of enthusiastic and fairly intelligent senior students to tutor junior students through discussion, problem solving and demonstration of important topics in the course. The experience of both faculty and students involved in the entire process has endorsed that this approach creates an effective learning environment, wherein all stakeholders like department, faculty, junior and senior students are benefited.
\end{abstract}

Keywords- tutor, education

Uma Boregowda,

Department of Computer Science and Engineering, Malnad College of Engineering, Hassan, India umaboregowda@gmail.com

\section{Introduction}

Premier institutes often use post graduate students and research scholars as teaching assistants (TAs) to conduct the courses more effectively and to give more time for the professors to engage in research, administration and consultation works. TA duties encompass answering student queries, grading assignments, leading periodical discussions and at times valuing test papers. This benefits all the parties: instructors benefit from reduced workload and thus can concentrate on more productive works, TAs receive training as teachers and students gain more comfort in acquiring knowledge and clearing their doubts [1].

Many engineering colleges in India cannot afford to have TAs, as they do not run post graduate courses in sufficient number and it is expensive. This provoked us to think of an alternative way to assist students in better learning of the courses. The idea we came up with is to use senior students to help junior students by playing the role of tutor but not as a full TA. The major focus is to improve learning and performance of junior students.

A search in the internet showed that similar kinds of attempts are carried out at several other institutes. The seminal work by Wild et al. [2] has shown that students enjoyed the learning environment, reported more positive mood, and showed greater exploratory activities. This further strengthened our confidence to continue with our ensued approach to help students in their courses. 
The aim of the entire process is to benefit junior students in several dimensions like - better understanding of the concepts underlying the course, improved relationship with both seniors and peers, possible exploratory activities in the course and getting a good role model by means of tutors. The senior tutoring students, in turn, are expected to enhance their knowledge of the course, to gain valuable teaching experience and to develop leadership skills.

\section{Related work}

There is a long tradition of using students and undergraduate students as TAs [4]. The use of undergraduates as TAs is experimented in many institutes since 30 years, mainly as a cost cutting measure. But Reges et al. at Stanford University [3] were the first to present their experience. Stanford continued this program for several years and streamlined the entire structure and recorded the observed outcomes [4]. Their findings showed that this approach increased the rapport between TAs and students, and that TAs often acted as role models for students.

Reges took along with him the idea of undergraduate TAs when he moved to University of Arizona [5]. The same positive results were observed along with enhanced sense of community among students which was lacking then. An undergraduate consultant program similar to undergraduate TAs was implemented at Montana State University [6]. The senior students were used to assist faculty members in laboratory sessions. The junior students found the assistants to be more effective at answering their questions and helping them.

Appalachian State University implemented a peer mentoring program [7] where undergraduate mentors interacted one-on-one with students outside the formal class time. It was found that learning of both mentor and students was benefitted.

The University at Buffalo, SUNY used undergraduate TAs specifically to enhance the level of teaching [8]. Because they had many bad experiences with graduate TAs as they failed to relate to students and did not fully understand the program at the university. The author report that undergraduate TAs went to the extent of taking the responsibility of improving the course contents, kind of assignments and changed discussion sessions to laboratory sessions. As a result of these changes, student satisfaction raised higher.

It has become quite common to use undergraduate TAs in several institutes for larger classes where it is very difficult to run the courses without them. All the above mentioned papers describe the success of using undergraduate TAs always in the context of providing required additional help for the professor. But we have used undergraduate students as tutors and not as TAs in our small college environment. And the goal is to provide supplemental help to students for better learning than reducing the workload of faculty members.

The tutoring is intended to provide scaffolding for students. Scaffolding is a metaphor originally used in developmental psychology to describe how a child learns with the assistance of a parent [9]. It means to provide proper-timed support to the learner's learning process, so that she/he can achieve the learning objectives that could not have been attained on his own.

\section{Tutoring program}

The proposed program is experimented for the course on Microprocessor in the computer science department.

\section{A. Structure}

The students are split into several small groups with 6-8 members in each and a senior student who plays the role of tutor is assigned to individual groups. Students meet twice in a week for tutor sessions, each lasting for an hour. Tutors are handpicked by the faculty member based on their academic performance, attitudes and content knowledge. Few interested students who volunteer themselves are also chosen to work as tutors. Thus we pool a group of potential, interested and enthusiastic tutors. The course has 75-80 enrolled students, 10-12 tutors and follows the below staff:

口 Course Instructor: The faculty member who lectures and has the primary responsibility of the course.

u Coordinator Tutor: A candidate chosen among tutors to work directly with the instructor in order to help administer the course. $\mathrm{He} / \mathrm{she}$ discusses with faculty, other tutors about what contents, how 
and when they are to be delivered to the students. Regular meetings are held to discuss and share their best practices in reaching out the students.

u Tutor: The senior student who holds sessions with the students. Their major task is to assist students in understanding the course contents. They do the major bulk of work.

\section{B. Positive Features of this Program}

The experience of this program has demonstrated several positive aspects to all the stake holders.

\section{Benefits to Students}

口 The students get a more relaxed classroom environment to better understand the concepts, to clarify their doubts and to receive better attention.

口 This process brings in profound positive effects especially on slow learning students, in terms of their learning and increased confidence in the course.

( Intelligent students will get an opportunity to interact with more knowledgeable tutors, which motivates and helps them to carry out more exploratory activities in the course.

( Enables to build good relation with senior and peer students, which helps them in many aspects.

\section{Benefits to Tutors}

( This serves as a training ground for future teachers, as tutors develop excellent teaching and communication skills.

( In the process of learning to explain the concepts to the group of students, tutor's own understandings of those concepts increases dramatically and also often revealed their own misunderstandings.

$\square$ Leading the group in discussions and other activities, tutors gain valuable experience on technical, inter-and intra-personal aspects and in developing leadership skills.

口 They included this experience in their resume and spoke about the same during job interviews.

口 Tutors are well recognized in the entire department, campus and also with student's parents, because of their role in assisting students.

Benefits to Faculty and Department

૫ The reputation and popularity of the whole course in the institute increases.

口 The strength of one-to-one interaction between students improves, thus creating a community within the department.

( Results in improved faculty-student interaction and relation.

\section{Impact of Tutoring Program}

The main purpose of conducting tutoring classes effectively is to improve student performance. One direct way to measure the same is to use the results of students in the course for which tutoring were done. The comparison of student result with tutoring is compared with that of previous year when tutoring was not conducted is shown in Fig. 1. It is evident from Fig. 1 that there is an improvement in the performance by $8-12 \%$, which indicates the success of the tutor program. Further improvements can be achieved by making tutoring more effective.

Students expressed their happiness about the tutoring program they underwent. To evaluate the impact of this on students, we conducted a survey. The questionnaire included few Liker-scale questions and one open question regarding the students' expectation of the tutoring program (based on 10 scale system: 1 being the least and 10 being the maximum). The criteria for evaluation and the results are tabulated in the table 1 . The average value for each criteria, along with standard deviation are shown in table 1 .

To measure the expectations and experience gain of tutors, evaluation questionnaire was also given to the tutor. The feedback is summarized in table 2 .

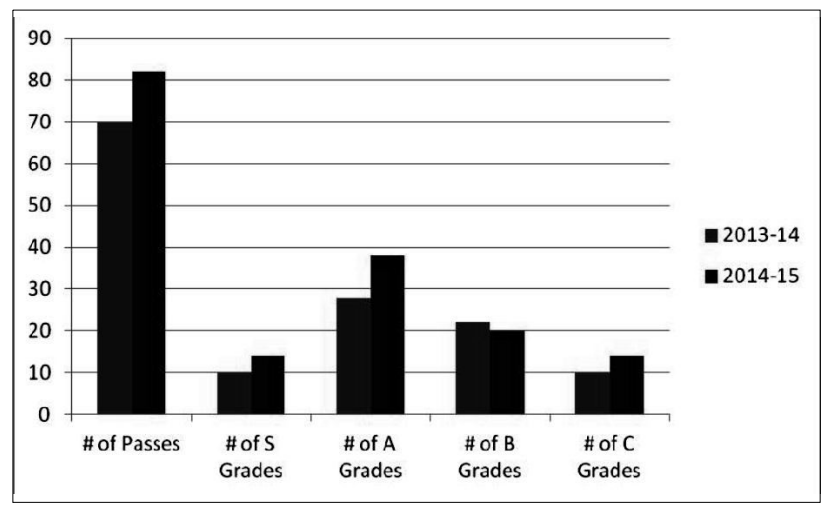

Figure 1. Comparison of Student Results of 2 years with and without Tutoring 
Table 1. Feedback Result from Students

\begin{tabular}{|l|c|}
\hline Criteria & $\begin{array}{l}\text { Average } \\
\text { (Standard } \\
\text { Deviation) }\end{array}$ \\
\hline $\begin{array}{l}\text { Influence of the tutoring program on } \\
\text { my success in the course }\end{array}$ & $8.2(1.4)$ \\
\hline $\begin{array}{l}\text { Helped in building a strong foundation } \\
\text { of my discipline }\end{array}$ & $9.1(1.56)$ \\
\hline $\begin{array}{l}\text { Clarified my doubts and solved my } \\
\text { problems }\end{array}$ & $7.8(2.4)$ \\
\hline Influence on my college life & $8.4(2.7)$ \\
\hline Meeting my expectations & \\
\hline
\end{tabular}

Table 2. Feedback Result from Tutors

\begin{tabular}{|l|c|}
\hline Criteria & $\begin{array}{l}\text { Average } \\
\text { (Standard } \\
\text { Deviation) }\end{array}$ \\
\hline Overall experience rating & $9(1.3)$ \\
\hline Enhanced teaching skill & $9.2(1.4)$ \\
\hline $\begin{array}{l}\text { Honing technical and leadership } \\
\text { skills }\end{array}$ & $8.4(2)$ \\
\hline $\begin{array}{l}\text { Improved relation and interaction } \\
\text { with } \\
\text { juniors and peers }\end{array}$ & $9.3(1.4)$ \\
\hline
\end{tabular}

The Liker-scale questions allowed us to discover students' perception of the degree to which tutoring program assign their course success, students' perception of the degree to which tutor assisted their success in the course, influenced their college life, participated in building a strong foundation of their discipline, helped to choose their future career path and made them feel more a member of the department "family."

The feedback from both students and tutors indicated that tutoring program was seen as a success and it received pretty good scores. Out of 80 feedbacks, 60 were very positive, while 20 had negative remarks commenting on the not so good ability of the tutor to teach or to solve their doubts.

\section{Conclusion And Future Improvements}

In our experience, use of undergraduates to tutor junior students has proven to be useful and an effective way to provide better teaching support for engineering courses. The process provides an opportunity for the students to get an opportunity to interact with more knowledgeable students and thus acquire more knowledge. This provides a platform for tutors to hone their skill sets, gain valuable experience in teaching and more productive interaction with junior students. This scheme benefits participating students, tutors and the department as a whole.

The observations made in tutoring session and students feedback, the need is felt to train and guide tutor, so that they can be more productive and useful to the students. Also tutors must be selected based on their course knowledge, teaching ability and attitude. This to a greater extent ensures greater quality in the program. To attract able students for tutoring some incentives must be awarded and few possibilities are to give credits or some financial benefits. It is also required to give a more formal structure to the entire program.

\section{References}

[1] Goldschmid, B. and Goldschmid, M.L., "Peer Teaching in Higher Education: a Review", Higher Education 5, 9-33, 1976

[2] Wild, T. C., Enzle, M. E., and Hawkins W. L., "Effects of Perceived Extrinsic versus Intrinsic Teacher Motivation on Student Reactions to Skill Acquisition", Personality and Social Psychology Bulletin 18,pg 245-251, 1992

[3] Stuart Reges, John McGrory, and Jeff Smith. "The Effective use of Undergraduates to Staff Large Introductory CS Courses", SIGCSE Bulletin, 20(1):22-25, 1988

[4] Eric Roberts, John Lilly, and Bryan Rollins, "Using Undergraduates as Teaching Assistants in Introductory Programming Courses: An Update on the Stanford Experience", SIGCSE '95: Proceedings of the twenty-sixth SIGCSE technical symposium on Computer science education, pages 48-52, New York, NY, USA, 1995. ACM.

[5] Stuart Reges, "Using Undergraduates as Teaching Assistants at a State University", In SIGCSE'03:Proceedings of the 34th SIGCSE technical symposium on Computer science education, pages 103-107, New York, NY, USA, 2003. ACM.

[6] John Paxton. "Undergraduate Consultation: Opportunities and Challenges", Journal of Computing Science in Colleges, 21(1):231-238, 2005. 
[7]Rahman Tashakkori, James T. Wilkes, and Edward G. Pekarek, "A Systemic Mentoring Model in Computer Science", In ACM-SE 43: Proceedings of the 43rd annual Southeast regional conference, pages 371-375, New York, NY, USA, 2005. ACM.

[8] Adrienne Decker, Phil Ventura, and Christopher Egert, "Through the Looking Glass: Reflections on
Using Undergraduate Teaching Assistants in CS1", SIGCSE Bull., 38(1):46-50, 2006.

[9]D.Wood, J. S. Bruner, and G. Ross. "The Role of Tutoring in problem solving", The Journal of Child Psychology and Psychiatry and Allied Disciplines, 17(2):89, 1976. 